\title{
Clinical evaluation of 4-channel ambulatory EEG monitoring in the management of patients with epilepsy
}

\author{
JOLYON OXLEY, MARGARET ROBERTS \\ From the Chalfont Centre for Epilepsy, Chalfont St Peter, Buckinghamshire, UK
}

SUMMARY The role of 4-channel EEG taped monitoring in the management of patients with $\vec{\omega}$ severe epilepsy has been evaluated, by examining the recordings from 100 consecutive patients referred for monitoring. Six main reasons for referral have been identified and in $80 \%$ of subjects the relevant clinical event was recorded, leading directly to a change in treatment in $57 \%$ of $\stackrel{\circ}{\infty}$ cases. This technique has proved to be cost effective and reliable and is particularly valuable in 6 the identification of pseudo seizures.

The use of EEG monitoring in the diagnosis and management of patients with epilepsy is now well established. Many authors have published data derived from the two monitoring techniques that have been developed, namely 8 or 16 channel video telemetry and taped ambulatory monitoring (see review by Binnie). ${ }^{1}$ Only a few authors ${ }^{2}{ }^{3}$ have, however, examined the clinical value of these techniques in a systematic way. Four-channel taped ambulatory monitoring has been available for clinical use at the Chalfont Centre for Epilepsy since 1980. The results from 100 consecutive in-patients referred for monitoring are presented and the value of this technique within the clinical setting is discussed with particular reference to the recent development of an 8-channel ambulatory monitoring system.

\section{Subjects and methods}

All subjects were adults (age range 16-50 years) who had been admitted to the Centre for a period of assessment, or who were in long term residential care. All had previously been diagnosed as suffering from epilepsy, and the IQ range was 65 to 110 . The majority experienced frequent seizures which had not previously responded to drug

Address for reprint requests: Dr Jolyon Oxley, Chalfont Centre for Epilepsy, Chalfont St Peter, Bucks, SL9 0RJ, UK.

Received 27 November 1984. Accepted 12 January 1985 treatment. Following routine assessment, including sta용 dard 16 channel EEG recording, 4-channel taped EE monitoring was performed in an attempt to solve a numbe्र $\mathbb{D}$ of clinical problems (see below).

Recordings were undertaken using the Oxford Mediç Systems Medilog 4-cassette tape recorder, standard C1 tapes, silver electrodes, and on-head pre-amplifiers (ONS HDX-82). The recorder had been modified to give 4 chan $\overrightarrow{\hat{n}^{+}}$ nels of EEG signal, rather than the usual three, and the of event marker signal was superimposed on one channel. $A$ : standardised electrode placement was used (F4-C4; T4-O T6; F3-C3; T3-T5) unless the 16 channel recording suggested that an alternative montage would be more $\overline{0}$ profitable. Subjects remained under observation through- صి out the recording.

Normal activity was encouraged and tapes were marked $\stackrel{2}{\Rightarrow}$ using the event marker button and a written record made on a standardised form when any clinical events occurred. The recording was continued until at least one clinical event occurred, or until the subject wished to discontinue? the recording. The system was checked every 24 hours when the batteries were renewed and the electrodes rejellied. Recordings were analysed using the OMS Page Mode Display at a speed of $20 \times$ real time. Paper print $-\underline{3}$ outs were made where appropriate.

\section{Results}

A retrospective analysis of the results of taped EEG monitoring in 100 consecutive patients is presented in the table, according to the presenting clinicaln problem. Six reasons for referral were identified:

1 To confirm the diagnosis of epilepsy in patients 0 930 
Table Data from 100 consecutive patients recorded using 4 channel EEG taped monitoring analysed according to presenting clinical problem

\begin{tabular}{|c|c|c|c|c|c|c|c|}
\hline & Diagnosis & $\begin{array}{l}\text { Nature and } \\
\text { frequency of } \\
\text { attacks }\end{array}$ & $\begin{array}{l}\text { Mental } \\
\text { state }\end{array}$ & Incontinence & $\begin{array}{l}\text { Control of } \\
\text { seizures }\end{array}$ & $\begin{array}{l}\text { Origin of } \\
\text { seizures }\end{array}$ & Totals \\
\hline $\begin{array}{l}\text { Total recorded } \\
\text { Clinical events recorded } \\
\text { Negative investigation } \\
\text { Event related to }\end{array}$ & $\begin{array}{r}20 \\
19 \\
1\end{array}$ & $\begin{array}{r}35 \\
31 \\
4\end{array}$ & $\begin{array}{l}8 \\
7 \\
1\end{array}$ & $\begin{array}{r}12 \\
9 \\
3\end{array}$ & $\begin{array}{r}18 \\
15 \\
3\end{array}$ & $\begin{array}{l}7 \\
5 \\
2\end{array}$ & $\begin{array}{r}100 \\
86 \\
14\end{array}$ \\
\hline $\begin{array}{l}\text { epileptic activity } \\
\text { Event not related to }\end{array}$ & 1 & 25 & 6 & 2 & 15 & 5 & 54 \\
\hline $\begin{array}{l}\text { epileptic activity } \\
\text { Treatment changed }\end{array}$ & $\begin{array}{l}18 \\
15\end{array}$ & $\begin{array}{r}6 \\
22\end{array}$ & $\begin{array}{l}1 \\
4\end{array}$ & $\begin{array}{l}7 \\
8\end{array}$ & $\begin{array}{l}0 \\
8\end{array}$ & $\begin{array}{l}0 \\
0\end{array}$ & $\begin{array}{l}32 \\
57\end{array}$ \\
\hline
\end{tabular}

whose seizures were thought clinically to be pseudo seizures.

2 To ascertain the nature and frequency of minor disturbances in patients who were known to have epilepsy.

3 To ascertain the cause of an abnormal mental state (usually confused or withdrawn behaviour).

4 To ascertain the cause of urinary incontinence which was not obviously associated with a seizure.

5 To identify the nature of seizure related EEG activity in an attempt to improve seizure control

6 To identify the site of origin of seizure activity.

Twelve per cent of subjects were recorded overnight, $70 \%$ for 24 hours and $18 \%$ for more than 24 hours (range 48-216 hours). In $11 \%$ of subjects a technical fault developed during the recording (usually loss of one channel) but in only one subject did the system fail to record during a seizure (due to battery exhaustion). The procedure was well tolerated by all subjects, and in $86 \%$ the relevant clinical event (seizure, incontinence, abnormal mental state etc) occurred during the period of the recording. In another four subjects useful additional information was obtained despite no clinical events occurring. The information provided led directly to a change in treatment (drug adjustment or new treatment instituted) in $57 \%$ of subjects.

\section{Discussion}

The high capture rate of clinical events $(86 \%)$ in this series is in keeping with the findings of Declerck et al. ${ }^{3}$ Using the Medilog 4-24 ambulatory system, they defined the three main indications for monitoring as (a) determining the frequency, timing and duration of epileptic EEG paroxysms, (b) identification of the type of epilepsy and (c) confirmation of a clinical diagnosis that attacks were non-epileptic. They reported a high yield of recorded epileptic paroxysms and further useful information for differential diagnosis in up to $88 \%$ of subjects studied.

Aarts et $a l^{2}$ reported being able to answer the referral question in 262 out of 324 recordings
$(81 \%)$ using 16 channel cable telemetry. Binnie' has reported that the results from $56 \%$ of these recordings led to a change in patient management, resulting in a $35 \%$ improvement rate in the clinical state of the patients. In this present series the information obtained from taped monitoring led directly to a change in treatment in $57 \%$ of patients. No attempt has been made in this study to evaluate the efficacy of such changes, as it was felt that such adjustments would be too subjective.

The most striking findings are seen in the 20 patients in whom it was felt, on clinical grounds, that their attacks were pseudo-seizures. In 18 out of the 19 subjects whose attacks were recorded, no epileptic activity was seen at the time of an attack, and normal EEG rhythms were noted as soon as movement and muscle artefact subsided. As all these attacks were pseudo convulsive seizures, this negative EEG finding supported by clinical observation and neuroendocrine studies ${ }^{4}$ has been sufficient to revise the diagnosis of epilepsy in most of these cases. This group of patients is the subject of a further long term study.

In the largest group of patients (35), however, there was no clinical doubt about the diagnosis. Monitoring was carried out to elucidate the nature and frequency of other intermittent symptoms, often sensory disturbances, which were not witnessed by attendant staff. Thirty one subjects had an attack during the recording and in 25 cases the symptoms were accompanied by paroxysmal epileptic activity. Patients were found either to be accurate in their estimation of the frequency of these disturbances, or to under-estimate them. It is difficult to comment on the six cases in whom the events were not related to EEG disturbances, as the limitations of 4 channel recording with surface electrodes in this situation are well known. ${ }^{5}$

The patients with abnormal mental states who were studied displayed either withdrawn behaviour or prolonged confusion. In six out of seven the abnormal behaviour was found to be related to prolonged sub-clinical epileptic activity. We have not attempted to study patients prone to outbursts of 
aggressive behaviour using this technique, because of possible damage to the equipment.

Incontinence of urine is a fairly common feature of generalised seizures, but 12 patients in this series were often incontinent without a clinical seizure being noted. The majority were incontinent during sleep and they were studied using overnight taped EEG recording and an incontinence alarm. In seven patients incontinence was not found to be associated with epileptic activity and in only two did incontinence coincide with generalised paroxysmal dischanges. It is clearly important to establish the cause of incontinence in these patients and not just to assume that it is due to the epilipsy, as the treatment will be very different.

The remaining 25 patients were referred for monitoring because their seizures were intractable, and more information was requested about the nature and origin of EEG activity at the time of seizures, in order to guide modifications to their treatment. Although the yield of seizure related EEG information was $(20 / 25)$, treatment was changed in only eight patients as a result. This is no doubt because rather little is yet known about the relationship between seizure related EEG activity and appropriate drug treatment. Two of the patients were referred elsewhere for investigations with a view to neurosurgery, but 4 channel monitoring is too limited in scope to be of much value in an assessment for surgery.

When evaluating any technology for routine clinical use it is important to consider reliability and cost effectiveness. Although technical faults developed during the recording period of $11 \%$ of subjects, this only resulted in total loss of signal in one case. It must also be remembered that many of the patients were having frequent seizures, sometimes accompanied by falling and injury to the head, and some may have interfered with the equipment because of their limited understanding. The cassette tape recorders have required repair on occasion, but the frequency of breakdowns and the cost of repairs is acceptable. The play back unit has not developed a fault in 4 years of use. We estimate that the cost of 24 hour recording is about $2^{1 / 2}$ times that of a standard 20 minute 16 channel recording, largely because of the extended period needed for analysis. The yield of new EEG information in this series is high, partly because of the severity of the epilepsy in these subjects, but also because they were inpatients and therefore available for recording when clinical events were most likely to occur. Extended recordings are also quite feasible and the equipment does not need constant supervision while in operation, nor sophisticated on-site technical support. The main limitations of this technique are the small number of EEG channels and the lack of visual record of clinical events. The recent development of a commercial 8 channel ambulatory monitoring system $^{6}$ will partly remedy the first of these deficiencies. However, in view of the high yield of clinically relevant information from 4 channel ambulatory monitoring, we suggest that this technique will still have a useful role particularly in the management of patients with severe epilepsy, in whom epileptic disturbances tend to be generalised. An 8 channel system will undoubtedly improve the localisation of the origin of epileptic discharges and may assist with the 흠 differential diagnosis of attacks with only sensory $\frac{\bar{c}}{\sigma}$ symptoms. However, because of the considerable $\Phi$ extra cost of this system it is unlikely to become widely available and the benefits of 4 channel os monitoring at an early stage should not be overlooked, particularly in patients in whom there is $\overrightarrow{\vec{\omega}}$ clinical doubt about the diagnosis of epilepsy.

In order to guide the most effective development of EEG services a comparative study examining 4 ? and 8 channel ambulatory monitoring and 8 and $16 \stackrel{\circ}{\circ}$ channel video telemetry is badly needed.

We are grateful to all members of staff who assistea with the clinical evaluations, to Dr Simon Shorvon for his helpful comments and to Mrs Joanna Ropg $\vec{g}$ for preparing the typescript.

\section{References}

' Binnie CD. Telemetric EEG monitoring in epilepsy. Pedley TA, Meldrum BS, eds. Recent Advances in $\vec{c}$ Epilepsy. Edinburgh: Churchill Livingstone, o 1983:155-78.

${ }^{2}$ Aarts JHP, Binnie CD, Van Bentum-de Boer PTE, et al. The value of telemetric EEG monitoring in epilepsy. Br J Clin Pract (Symposium Supplement 18) 1982:5- 응 7.

${ }^{3}$ Declerck AC, Martens WLJ, Schiltz AM. Evaluation of $\frac{2}{\triangleright}$ ambulatory EEG cassette recording. In: Stefan $\mathrm{H}, \stackrel{2}{\Rightarrow}$ Burr W, eds. EEG Monitoring. Stuttgart: Gustav Fisher, 1982:29-36.

${ }^{4}$ Oxley J, Roberts M, Dana Haeri J, Trimble M. Evaluation of 4-channel EEG taped recordings and serum prolactin levels in the diagnosis of epileptic and nonepileptic seizures. In: Dam M, Gram L, Penry JK, eds. Advances in Epileptology-XIIth Epilepsy International Symposium. New York: Raven Press, 1981:343-55.

${ }^{5}$ Ives JR, Woods JF. A study of 100 patients with focal 8 epilepsy using a four channel ambulatory cassette recorder. In: Stott FD, Raftery EB, Goulding L, eds. 을 Proceedings of the Third International Symposium on Ambulatory Monitoring, ISAM. London: Academic $\frac{\mathrm{O}}{2}$ Press, 1980:383-92.

- Stores G. Clinical and EEG evaluation of neuro- N psychiatric disorders. J Am Acad Child Psychiatry (in press). 